\title{
Forum
}

\section{Determining the Optimum Course to Join a Fair Current/Cross a Foul Current}

\author{
T. Fales
}

1. INTRODUCTION. This paper presents a formula which enables the navigator to determine the most advantageous point at which to join a fair current, and the most advantageous course to steer when he must cross a foul current. The formula is derived, and its application and methods of estimating the factors of the equation are discussed.

2. MATHEMATICAL SOLUTION OF THE OPTIMAL USE OF CURRENT PROBLEM. Making optimal use of a fair current or determining the best course to cross a foul current are considerations which must have concerned navigators long before the development of celestial navigation, yet no currently available navigational text attempts a mathematical definition of the problem. A relatively simple formula provides an answer accurate to the nearest 0.1 nautical mile. Since current drift and vessel speed in the immediate or near future can rarely be determined with much greater accuracy, this degree of precision seems adequate. Certainly, any reasonable calculation is preferable to pure guesswork.

3. Definition ofthe fair/foul current problem. Referring to Fig. I, a vessel at point $P$ wants to reach point $A$ in the shortest possible time. The line $B A$ represents the axis of a favourable current and $X$ is the point where the ship should join the axis to achieve this objective.

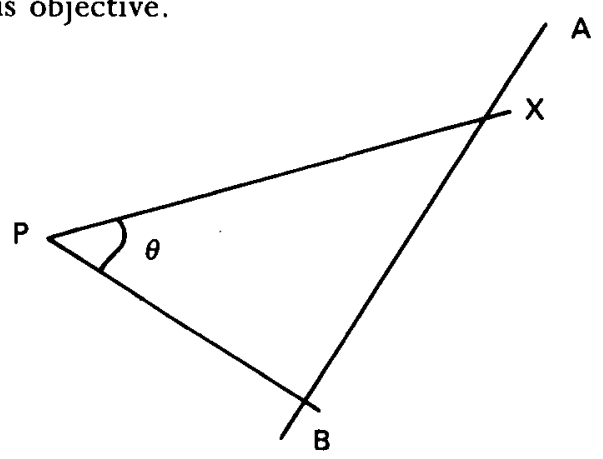

Fig. I. Definition of problem

If the vessel's speed in still water is $V$, the average speed from point $\mathrm{P}$ to point $\mathrm{X}$ is $V_{1}$, the vessel's speed plus maximum drift is $V_{2}, T$ is the time required to reach point $A$, from point $P, t_{1}$ is the time required to go from $P$ to $X$, and $t_{2}$ is the time required to go from $X$ to $A$,

then

$$
\begin{gathered}
T=t_{1}+t_{2} \\
t_{1}=\left(a^{2}+x^{2}\right)^{\frac{1}{2}} / V_{1}, \\
t_{2}=\mathrm{XA} / V_{2}
\end{gathered}
$$


where $a$ is the perpendicular distance from $P$ to the current axis at $B$, and $x$ is the distance $\mathrm{BX}$.

4. ESTIMATING VESSEL'S SPEED CROSSING THE CURRENT. The current's drift is not constant from point $P$ to the current's axis on line $A B$. If the current's drift at its axis is three knots and point $P$ is at the current's edge where drift is zero, the vessel will encounter a favourable current, varying from o to 3 knots along the course line PX.

To calculate $t_{1}$, the navigator must estimate the average speed his vessel will make good over the distance PX. He must estimate because the change in the rate of drift is most probably described by an exponential or parabolic curve rather than by a straight line, and because he does not know the form of the curve, nor does he know, at this point, the angle his course from point $P$ to point $X$ will make with the axis of the set. He does know, from his charts and from the sailing directions, the general position of the current's axis and its mean set and drift at the axis,

then $\quad D_{\mathrm{a}}=D / 2$

where $\quad D_{\mathbf{a}}=$ average drift ;

$D=$ drift at axis or maximum drift

should provide a reasonable approximation of the average favourable drift.

If a foul current is to be crossed, maximum drift and hence maximum speed will be found on the other side of the current and in the axis of the counter current. If there is no counter current, then maximum speed, $V_{2}$, will be found in still water.

Often a vessel must cross a foul current with fair counter currents on both sides and a band of still water on one or both sides. In such cases, the formula for estimating the average speed, $V_{1}$, of the vessel may be written:

$$
V_{1}=V+\left[\left(D_{1} W_{1} / 2\right)+\left(D_{2} W_{2} / 2\right) \ldots+\left(D_{n} W_{n} / 2\right)\right] / a
$$

where $V_{1}=$ ship's average speed crossing successive bands of fair or foul current or of still water; $V=$ ship's speed in still water; $D_{\mathrm{n}}=$ maximum drift in band $\mathrm{n} ; W_{\mathrm{n}}=$ width of band $n$ measured on the $a$ axis; $a=$ total width of bands (or PB in Fig. 1 )

A foul drift will naturally be preceded by a minus sign and a band of still water will have a value equal to zero since $D_{\mathrm{n}}$ will be zero. This algorithm may be used to estimate the value of $V_{1}$ when crossing any number of contiguous bands of fair or foul current or still water.

5. DERIVATION OF FORMULA TO FIND POINT X AND ANGLE $\theta$. It is evident from formulas $(\mathrm{I}),(2)$ and (3) that

$$
T=\left(a^{2}+x^{2}\right)^{\frac{1}{2}} / V_{1}+(y-x) / V_{2}
$$

where $y$ is the distance $B A$.

To find the minimum time, we differentiate the value for $T$ with respect to $x$ and equate it to zero. We note that $a, y$ and $V_{2}$ are constants and, at this stage, $V_{1}$ is also assumed to be constant.

$$
\left.\begin{array}{rl}
x\left(a^{2}+x^{2}\right)^{\frac{1}{2}} V_{1}-1 / V_{2} & =0 \\
\frac{x V_{2}-\left(a^{2}+x^{2}\right)^{\frac{1}{2}} V_{1}}{V_{1} V_{2}\left(a^{2}+x^{2}\right)^{\frac{1}{2}}} & =0 \\
x V_{2} & =\left(a^{2}+x^{2}\right)^{\frac{1}{2}} V_{1} \\
x^{2} V_{2}^{2} & =a^{2} V_{1}^{2}+x^{2} V_{1}^{2} \\
x & =\frac{a V_{1}}{\left(V_{2}^{2}-V_{1}^{2}\right)^{\frac{1}{2}}}
\end{array}\right\}
$$


where $\theta$ is the angle between $\mathrm{PX}$ and $\mathrm{PB}$.

6. CORRECTION TO ESTIMATE OF SHIP'S AVERAgE SPEED, $V_{1}$. Since the favourable current is not dead astern on the $P$ to $X$ course, nor is a foul current dead ahead on this leg, a small correction is desirable to achieve a reasonable degree of precision in the calculation. This correction is given by the formulae:

$$
V_{1}=V+\left(D_{\mathrm{a}} \sin \theta\right)
$$

The problem can now be reworked using the new value of $V_{1}$. Due to the simplicity of the formula, this should not be unduly laborious when using a calculator. When using a programmable calculator, only the second values of $x$ and need be displayed.

It is now only necessary to subtract $\theta$ from 90 degrees to obtain the difference between ship's heading and the current axis. The course to make good can then be found by adding or subtracting this difference to the current axis and the course to steer solved by diagram or other simple method of determining compensation for leeway.

\title{
'Trans-oceanic Passages by Rhumbline Sailing'
}

\author{
Matti A. Ranta \\ (Helsinki University of Technology)
}

The recent paper ${ }^{1}$ by Captain Ivica Tijardović describing trans-oceanic navigation, composed of a rhumbline and a latitude parallel sailing was very interesting. I would like to point out that the problem can be solved without meridional parts assuming a spherical Earth and taking the angles in radians.

According to formula (26) in my own recent paper $^{2}$ the combined distance is:

$$
D=\frac{\phi_{2}-\phi_{1}}{\cos \theta}+\left\{\lambda_{2}-\lambda_{1}-\left[\operatorname{ar} \sinh \left(\tan \phi_{2}\right)-\operatorname{ar} \sinh \left(\tan \phi_{1}\right)\right] \tan \theta\right\} \cos \phi_{2} .
$$

This is a minimum if $\theta$ is the solution of:

$$
\sin \theta=\frac{\left[\operatorname{ar} \sinh \left(\tan \phi_{2}\right)-\operatorname{ar} \sinh \left(\tan \phi_{1}\right)\right] \cos \phi_{2}}{\phi_{2}-\phi_{\mathrm{l}}} .
$$

The inverse hyperbolic sine is:

$$
\operatorname{ar} \sinh z=\ln \left(z+\sqrt{ }\left(z^{2}+1\right)\right) \text {. }
$$

There are given in the example given by Tijardović :

$$
\begin{array}{lll}
\text { Position I } & \phi_{1}=35^{\circ} \mathrm{N} & \lambda_{1}=140^{\circ} 30^{\prime} \mathrm{E} . \\
\text { Position 2 } & \phi_{2}=46^{\circ} 20^{\prime} \mathrm{N} & \lambda_{2}=124^{\circ} 30^{\prime} \mathrm{W} .
\end{array}
$$

The corresponding great circle distance is :

$$
D_{G}=4 \mathrm{I} \times 3.3 \mathrm{n} \cdot \mathrm{m} \text {. }
$$

with the initial heading of:

$$
H_{I}=47 \cdot 6^{\circ}
$$

